TITLE:

\title{
Effect of In additions on the thermoelectric properties of the type-I clathrate compound Ba8Ga16Ge30
}

\section{$\operatorname{AUTHOR}(S):$}

Okamoto, NL; Kishida, K; Tanaka, K; Inui, H

\section{CITATION:}

Okamoto, NL ... [et al]. Effect of In additions on the thermoelectric properties of the type-I clathrate compound Ba8Ga16Ge30. JOURNAL OF APPLIED PHYSICS 2007, 101(11): 113525.

ISSUE DATE:

2007-06-01

URL:

http://hdl.handle.net/2433/50069

\section{RIGHT:}

Copyright 2007 American Institute of Physics. This article may be downloaded for personal use only. Any other use requires prior permission of the author and the American Institute of Physics. 


\title{
Effect of In additions on the thermoelectric properties of the type-I clathrate compound $\mathrm{Ba}_{8} \mathrm{Ga}_{16} \mathrm{Ge}_{30}$
}

\author{
Norihiko L. Okamoto, ${ }^{a}$ Kyosuke Kishida, Katsushi Tanaka, and Haruyuki Inui \\ Department of Materials Science and Engineering, Kyoto University, Sakyo-ku, Kyoto 606-8501, Japan
}

(Received 26 February 2007; accepted 15 April 2007; published online 11 June 2007)

\begin{abstract}
The thermoelectric properties of quaternary type-I clathrate compounds, $\mathrm{Ba}_{8} \mathrm{Ga}_{16-x} \mathrm{In}_{x} \mathrm{Ge}_{30}(x$ $=0-9$ ), have been investigated as a function of In content and temperature. The substitution of In atoms for $\mathrm{Ga}$ atoms leads to a decrease in electrical resistivity, as well as a decrease in thermal conductivity. The decrease in electrical resisitivity is explained in terms of the In occupancy behavior in the $6 c$ sites, whereas the decrease in thermal conductivity in terms of the increased extent of the rattling motion of $\mathrm{Ba}$ atoms due to the increased lattice constant. As a result, the value of thermoelectric dimensionless figure of merit $(Z T)$ of $\mathrm{Ba}_{8} \mathrm{Ga}_{16} \mathrm{Ge}_{30}$ is improved by In substitutions from 0.49 to 1.03 at $670{ }^{\circ} \mathrm{C}$ when $x=6$. () 2007 American Institute of Physics. [DOI: $10.1063 / 1.2743815]$
\end{abstract}

\section{INTRODUCTION}

Clathrate compounds have a crystal structure consisting of polyhedral cages that encapsulate guest atoms which rattle inside the cages. The cages consist of group IV and/or III elements $(\mathrm{T})$ while the guest atoms $(\mathrm{M})$ are typically alkali metals or alkaline-earth metals. Clathrate compounds exhibit relatively low electrical resistivity, as well as very low lattice thermal conductivity if the rattling guest atoms scatter heatcarrying phonons but not the conduction electrons. ${ }^{1,2}$ Therefore, clathrate compounds have been investigated in recent years as promising thermoelectric materials, ${ }^{3}$ since the thermoelectric performance is evaluated with the dimensionless figure of merit, $Z T=\alpha^{2} T /(\rho \lambda)$, where $\alpha, \rho, \lambda$, and $T$ stand for Seebeck coefficient, electrical resistivity, thermal conductivity, and temperature, respectively. Clathrate compounds, to which intensive investigation as possible thermoelectric materials is recently made, are those categorized as "type I" with the chemical formula of $\mathrm{M}_{8} \mathrm{~T}_{46}$, in which the cubic unit cell consists of two pentagonal dodecahedra $\left(\mathrm{T}_{20}\right.$ cage $)$ and 6 tetrakaidecahedra ( $\mathrm{T}_{24}$ cage), which has two hexagonal faces and twelve pentagonal faces. ${ }^{4}$ The space group of type-I clathrate compounds is $P m \overline{3} n$ (Ref. 5) and the cage framework consists of three different sites: $6 c, 16 i$, and $24 k$. Guest atoms are located in $2 a$ and $6 d$ sites, which are the centers of the dodecahedral and tetrakaidecahedral cages, respectively. ${ }^{4}$ Low thermal conductivity of type-I clathrate compounds is considered to originate from the rattling motion of guest atoms in $6 d$ sites $^{6-9}$ in addition to the complex crystal structure, alloy scattering, electron-phonon scattering, and so on. The guest rattling motion is detected by $\mathrm{x}$-ray and neutron diffraction as an anomalously large atomic displacement parameter. $^{6-9}$

Recently, we have investigated the crystal structure and thermoelectric properties of $\mathrm{Ba}_{8} \mathrm{Ga}_{y} \mathrm{Ge}_{46-y}$ alloys $(y=0-18)$ as a function of $\mathrm{Ga}$ content and found that $\mathrm{Ba}_{8} \mathrm{Ga}_{16} \mathrm{Ge}_{30}$ ex-

\footnotetext{
a) Author to whom correspondence should be addressed; Fax: +81-75-7535461; electronic mail: nlokamoto@ucdavis.edu
}

hibits the highest $Z T$ value with the highest thermoelectric power factor, $P=\alpha^{2} / \rho$, and the lowest thermal conductivity among the samples investigated. ${ }^{10-12}$ On the basis of the charge compensation concept, no excess electron (charge carrier) is expected to exist in $\mathrm{Ba}_{8} \mathrm{Ga}_{16} \mathrm{Ge}_{30}$ because 16 electrons donated by eight $\mathrm{Ba}$ atoms per unit formula are fully compensated by sixteen Ga atoms (group III). Therefore, the complete charge compensation is considered to be necessary in order to obtain a high power factor. On the other hand, the value of lattice thermal conductivity of $\mathrm{Ba}_{8} \mathrm{Ga}_{y} \mathrm{Ge}_{46-y}$ alloys decreases with the increase in the split distance in the encapsulated $\mathrm{Ba}(2)$ guest atom site, which is deduced with the split-site model. ${ }^{13}$ Because the split distance in the $\mathrm{Ba}(2)$ site increases with the increase in the size of the encapsulating tetrakaidecahedral cage, ${ }^{13}$ the expansion of the cage is expected to be effective for further reduction of the lattice thermal conductivity.

Based on the above findings, substitution of In for $\mathrm{Ga}$ in $\mathrm{Ba}_{8} \mathrm{Ga}_{16} \mathrm{Ge}_{30}$ is expected to be beneficial in improving the thermoelectric properties of $\mathrm{Ba}_{8} \mathrm{Ga}_{16} \mathrm{Ge}_{30}$. As far as the total content of group III elements $(\mathrm{Ga}+\mathrm{In})$ remains 16 per unit formula, charge compensation may be achieved also in $\mathrm{Ba}_{8} \mathrm{Ga}_{16-x} \mathrm{In}_{x} \mathrm{Ge}_{30}$, maintaining the power factor. At the same time, In substitution is expected also to give rise to the reduction in lattice thermal conductivity because the lattice constant and thus the split distance in the $6 d$ sites may increase upon alloying with In due to the large atomic radius of In atoms $(0.144 \mathrm{~nm})$ when compared to those of $\mathrm{Ga}$ $(0.126 \mathrm{~nm})$ and $\mathrm{Ge}(0.122 \mathrm{~nm})$ atoms. ${ }^{14}$

In the present study, we investigate phase equilibria among phases existing near the type-I clathrate phase in the $\mathrm{Ba}-\mathrm{Ga}-\mathrm{In}-\mathrm{Ge}$ system in order to determine the solubility limit of In in the type-I clathrate phase. We also investigate the thermoelectric properties of $\mathrm{Ba}-\mathrm{Ga}-\mathrm{In}-\mathrm{Ge}$ quaternary type-I clathrate compounds as a function of In content and temperature in order to see how In additions are effective in improving the thermoelectric properties of $\mathrm{Ba}_{8} \mathrm{Ga}_{16} \mathrm{Ge}_{30}$. 

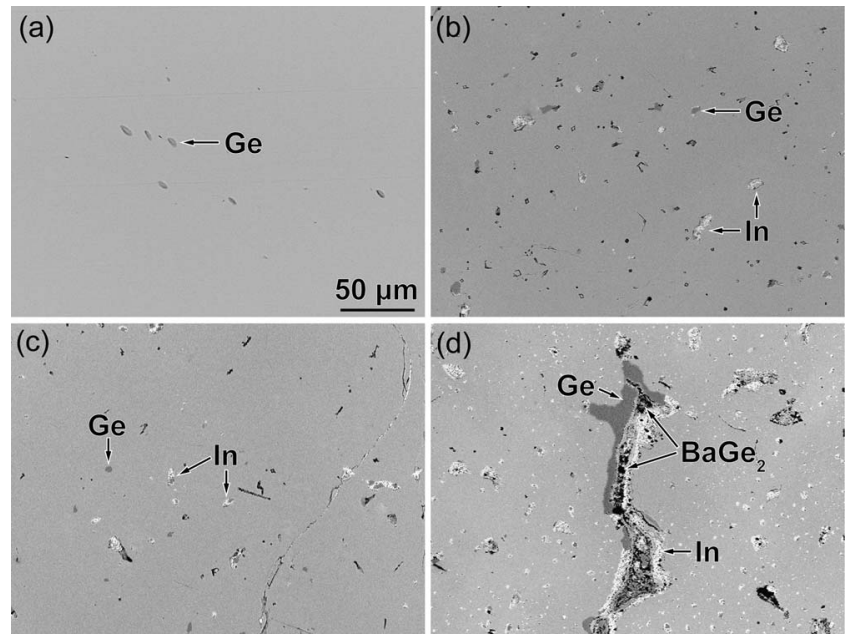

FIG. 1. Microstructures (SEM backscattered electron images) of $\mathrm{Ba}_{8} \mathrm{Ga}_{16-x} \mathrm{In}_{x} \mathrm{Ge}_{30}$ alloys with (a) $x=0$, (b) $x=3$, (c) $x=6$, and (d) $x=9$.

\section{EXPERIMENTAL PROCEDURES}

Specimens with nominal compositions of $\mathrm{Ba}_{8} \mathrm{Ga}_{16-x} \mathrm{In}_{x} \mathrm{Ge}_{30}(x=0,3,6$, and 9$)$ were prepared by $\mathrm{Ar}$ arc melting. After arc melting, specimens were annealed at $600{ }^{\circ} \mathrm{C}$ for $96 \mathrm{~h}$ followed by furnace cooling. Microstructures and chemical compositions of phases present in specimens were examined by scanning electron microscopy (SEM) and energy dispersive x-ray spectroscopy (EDS), respectively. Phase identification was made by $\mathrm{x}$-ray diffraction (XRD; $\mathrm{Cu} \mathrm{K} \alpha$ radiation) at room temperature. Measurements of electrical resistivity and Seebeck coefficient were made with our ULVAC ZEM-2 apparatus in the temperature range from room temperature to $670{ }^{\circ} \mathrm{C}$. Measurements of thermal conductivity $\left(\lambda_{\mathrm{RT}}\right)$ were carried out at room temperature by the static method. Values of thermal conductivity above room temperature $\left(\lambda_{T}\right)$ were calculated from the values of thermal diffusivity $\left(\kappa_{T}\right.$ and $\kappa_{\mathrm{RT}}$; those at a given temperature and room temperature, respectively) determined by the laser flash method with the following equation:

$$
\lambda_{T}=\lambda_{\mathrm{RT}} \kappa_{T} / \kappa_{\mathrm{RT}},
$$

on the basis that the value of specific heat for type-I clathrate compounds $\mathrm{Ba}_{8} \mathrm{Ga}_{16-x} \mathrm{In}_{x} \mathrm{Ge}_{30}$ is constant above room temperature. $^{15}$

\section{RESULTS}

\section{A. Microstructures}

SEM backscattered electron images of $\mathrm{Ba}_{8} \mathrm{Ga}_{16-x} \mathrm{In}_{x} \mathrm{Ge}_{30}$ alloys with $x=0,3,6$, and 9 are illustrated in Figs. 1(a)-1(d). Specimens with $x=0-6$ exhibit virtually a type-I clathrate single-phase microstructure although they contain a small volume fraction of Ge and/or In phases [Figs. 1(a)-1(c)], while that with $x=9$ exhibits a four-phase microstructure consisting of type-I clathrate, $\mathrm{Ge}, \mathrm{In}$, and $\mathrm{BaGe}_{2}$ phases [Fig. 1(d)]. The existence of $\mathrm{Ge}$ and In phases observed in specimens with $x=0,3$, and 6 [Figs. 1(a) -1 (c)] is considered to be due to the Ba evaporation during arc melting. EDS analysis indicates that the $\mathrm{BaGe}_{2}$ phase present in the specimen with $x=9$ possesses a chemical composition containing a non-
TABLE I. Ga, Ge, and In contents in the type-I clathrate compounds obtained by EDS analyses. The Ba sites are assumed to be fully occupied.

\begin{tabular}{ccccc}
\hline \hline $\begin{array}{c}\text { Nominal } \\
\text { composition }\end{array}$ & $\mathrm{Ga}$ & $\mathrm{In}$ & $\mathrm{Ge}$ & $\mathrm{Ga}+\mathrm{In}$ \\
\hline $\mathrm{Ba}_{8} \mathrm{Ga}_{16} \mathrm{Ge}_{30}$ & 16.3 & $\ldots$ & 28.3 & 16.3 \\
$\mathrm{Ba}_{8} \mathrm{Ga}_{13} \mathrm{In}_{3} \mathrm{Ge}_{30}$ & 13.5 & 2.4 & 29.6 & 15.9 \\
$\mathrm{Ba}_{8} \mathrm{Ga}_{10} \mathrm{In}_{6} \mathrm{Ge}_{30}$ & 10.5 & 4.9 & 29.8 & 15.4 \\
$\mathrm{Ba}_{8} \mathrm{Ga}_{7} \mathrm{In}_{9} \mathrm{Ge}_{30}$ & 8.9 & 6.3 & 29.8 & 15.2 \\
\hline \hline
\end{tabular}

negligible amount of $\mathrm{Ga}$ and In as well (Ba: Ga: In:Ge $=34.2: 4.3: 22.8: 38.7$ at. \%). The volume fraction of the Ge and In phases for the specimen with $x=9$ is much larger than that for the specimens with $x=3$ and 6 . These facts indicate that the solubility limit of indium in $\mathrm{Ba}_{8} \mathrm{Ga}_{16} \mathrm{Ge}_{30}$ is between $x=6$ and 9 when expressed in the form of $\mathrm{Ba}_{8} \mathrm{Ga}_{16-x} \mathrm{In}_{x} \mathrm{Ge}_{30}$.

Chemical compositions of the type-I clathrate compounds present in the specimens were analyzed by EDS, as tabulated in Table I. In the analyses, the Ba sites are assumed to be fully occupied (i.e., the Ba content is assumed to be 8 per unit formula). Although the In content analyzed by EDS increases monotonically as the value of $x$ in the nominal composition increases, the In content analyzed for the specimen with $x=9$ is smaller than that expected by extrapolating the In contents for specimens with $x=3$ and 6 . This is consistent with the fact that the solubility limit of indium in $\mathrm{Ba}_{8} \mathrm{Ga}_{16} \mathrm{Ge}_{30}$ is between 6 and 9 per unit formula. The total amount of group III elements $(\mathrm{Ga}+\mathrm{In})$ for all specimens is close to 16 , so that the charge compensation is almost achieved.

XRD patterns of $\mathrm{Ba}_{8} \mathrm{Ga}_{16-x} \mathrm{In}_{x} \mathrm{Ge}_{30}$ alloys with $x=0,3,6$, and 9 are shown in Fig. 2(a). Being consistent with the results from the SEM observations (Fig. 1), specimens with $x=0,3$, and 6 include a small volume fraction of Ge and/or In phases in addition to the type-I clathrate phase, while that with $x=9$ includes type-I clathrate, $\mathrm{Ge}, \mathrm{In}$, and $\mathrm{BaGe}_{2}$ phases. The variation of the lattice constant of the type-I clathrate phase with the In content is depicted in Fig. 2(b). As we expect from the relatively large atomic radius of indium in comparison with that of $\mathrm{Ga},{ }^{14}$ the lattice parameter of the type-I clathrate phase increases with the increase in the In content until the solubility limit of indium is reached between $x=6$ and 9. Based on the above results, phase equilibria among type-I clathrate, $\mathrm{Ge}, \mathrm{In}$, and $\mathrm{BaGe}_{2}$ phases are indicated in the corresponding quaternary phase diagram, as shown in Fig. 3.

\section{B. Thermoelectric properties}

The temperature dependence of electrical resistivity for the specimens investigated is of degenerate semiconductor, as shown in Fig. 4(a). The values of electrical resistivity for specimens with $x=3,6$, and 9 are all comparable with one another and are about one-third that for $\mathrm{Ba}_{8} \mathrm{Ga}_{16} \mathrm{Ge}_{30}$. The value of Seebeck coefficient for all specimens is negative in sign ( $n$-type conduction), and the absolute value generally increases with the increase in temperature, as shown in Fig. 4(b). The absolute values of Seebeck coefficient for all the In-substituted specimens are almost comparable with one an- 

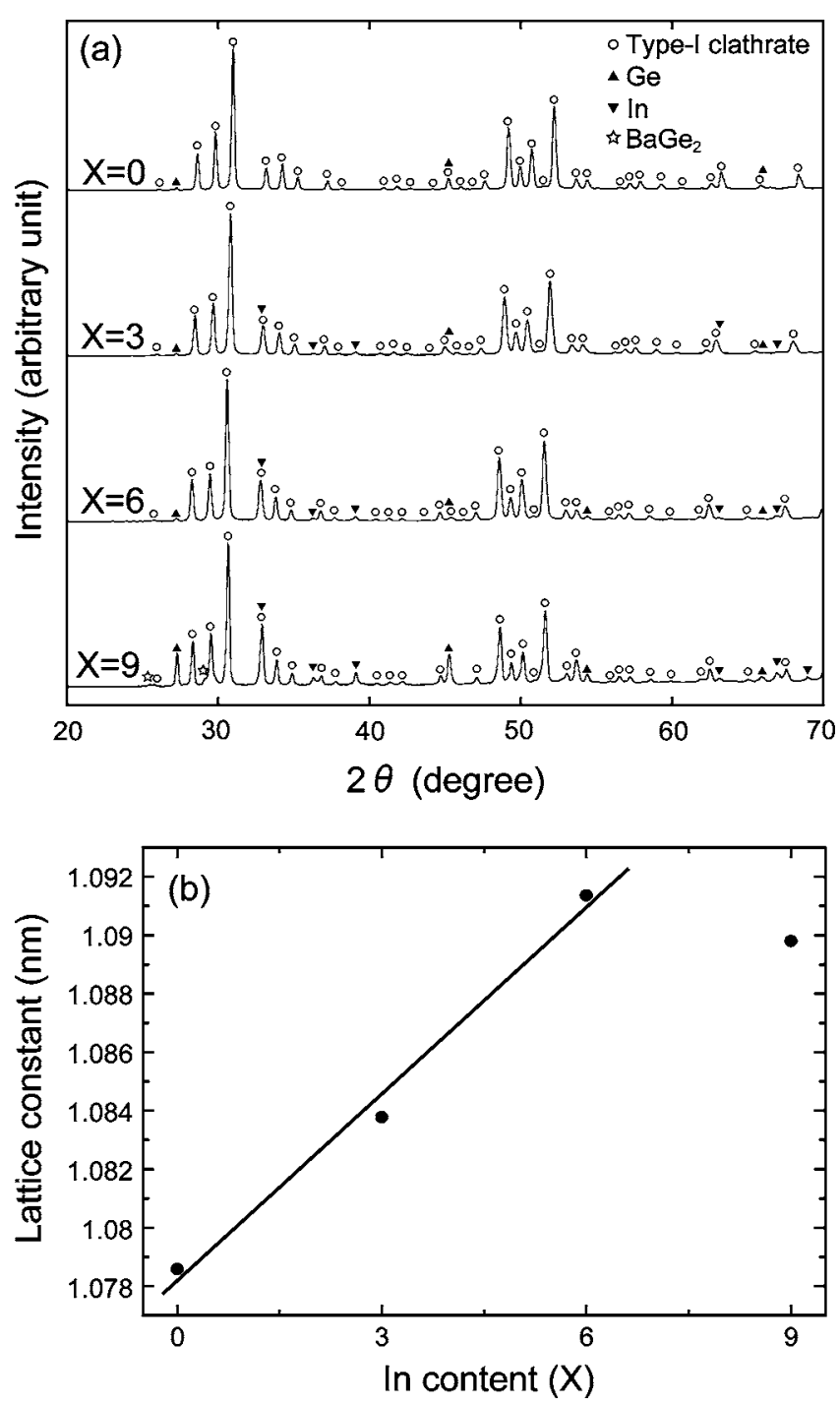

FIG. 2. (a) X-ray powder diffraction patterns of $\mathrm{Ba}_{8} \mathrm{Ga}_{16-x} \mathrm{In}_{x} \mathrm{Ge}_{30}$ alloys $(x=0,3,6$, and 9$)$ in the $2 \theta$ range from $10^{\circ}$ to $95^{\circ}$ and (b) lattice constant of the type-I clathrate phase plotted as a function of In content.

other and are smaller than that for $\mathrm{Ba}_{8} \mathrm{Ga}_{16} \mathrm{Ge}_{30}$. Figure 4(c) shows the temperature dependence of thermal conductivity for the specimens with $x=0-9$. The values of thermal conductivity for specimens with $x=3$ and 6 are comparable and are much smaller than that for $\mathrm{Ba}_{8} \mathrm{Ga}_{16} \mathrm{Ge}_{30}$. The value of thermal conductivity for the specimen with $x=9$ is between those for $\mathrm{Ba}_{8} \mathrm{Ga}_{16} \mathrm{Ge}_{30}$ and the specimens with $x=3$ and 6 . The $Z T$ values calculated with the obtained values of electrical resistivity, Seebeck coefficient, and thermal conductivity are plotted in Fig. 4(d) as a function of temperature. The ZT values for all specimens monotonically increase with the increase in temperature. The $Z T$ value for $\mathrm{Ba}_{8} \mathrm{Ga}_{16} \mathrm{Ge}_{30}$ is almost saturated at $670{ }^{\circ} \mathrm{C}$, whereas those for specimens with $x=3$ and 6 exhibit no tendency for saturation even at the highest temperature investigated. At temperatures above $350{ }^{\circ} \mathrm{C}$, the $Z T$ value increases with the increase in the In content until $x$ reaches 6 and again decreases when $x$ exceeds 6. The $Z T$ value for the In-substituted alloy with $x=6$ is as high as 1.03 at $670{ }^{\circ} \mathrm{C}$, which is more than twice that for the $\mathrm{Ba}_{8} \mathrm{Ga}_{16} \mathrm{Ge}_{30}$ ternary alloy $\left(0.49\right.$ at $\left.670{ }^{\circ} \mathrm{C}\right)$.

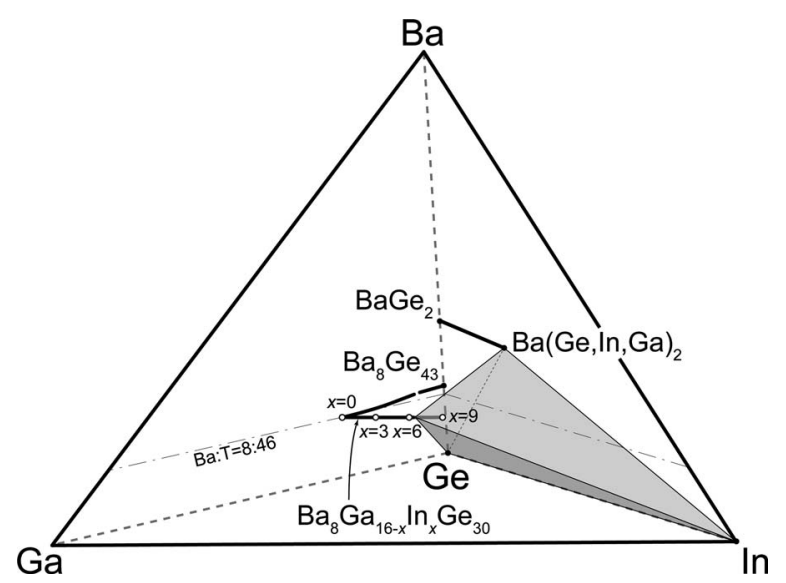

FIG. 3. Portions of the quaternary phase diagram in the Ba-Ga-In-Ge system. Open circles correspond to nominal compositions of specimens investigated. The ternary phase diagram in the $\mathrm{Ba}-\mathrm{Ga}-\mathrm{Ge}$ system is referred from Ref. 11 .

\section{DISCUSSION}

\section{A. Electrical conduction}

The concept of charge compensation successfully describes the changes in the electrical resistivity and Seebeck coefficient of type-I clathrate compounds in the $\mathrm{Ba}-\mathrm{Ga}-\mathrm{Ge}$ system upon alloying with Ga. ${ }^{12}$ According to this concept, charge compensation is expected to be fully achieved in $\mathrm{Ba}_{8} \mathrm{Ga}_{16-x} \mathrm{In}_{x} \mathrm{Ge}_{30}$, since 16 electrons donated by eight $\mathrm{Ba}$ atoms are all compensated by 16 lone pairs produced by 16 $\mathrm{Ga} / \mathrm{In}$ (group III) atoms. However, the conduction behavior of all the specimens with nominal compositions of $\mathrm{Ba}_{8} \mathrm{Ga}_{16-x} \mathrm{In}_{x} \mathrm{Ge}_{30}$ is $n$ type and is of degenerate semiconductor [Figs. 4(a) and 4(b)], indicating that there exist some excess electrons that behave as charge carriers in the type-I clathrate compounds.

The density functional calculations of $\mathrm{Ba}_{8} \mathrm{Ga}_{16} \mathrm{Ge}_{30}$ indicate that the lowest conduction band arises from bonding between the $\mathrm{Ba}$ atom in $6 d$ sites and the cage atoms in the hexagonal face of the tetrakaidecahedral cage. ${ }^{16}$ Since the hexagonal face consists of cage atoms in $6 c$ and $24 k$ sites, the occupancy behavior of In, Ga, and Ge atoms in the $6 c$ and $24 k$ sites is of great importance to determine the electrical conduction behavior of these $n$-type clathrate compounds $\mathrm{Ba}_{8} \mathrm{Ga}_{16-x} \mathrm{In}_{x} \mathrm{Ge}_{30}$. According to the theoretical calculation by Blake et al., ${ }^{16}$ the electron overlap between the guest atom and the cage framework plays an important role in the transfer of the valence electrons from the guest atoms to the cage framework; the larger is the atomic size of the guest atom, the more efficiently the valence electrons are transferred to the cage framework.

If there is a large atom in the cage framework, the electron overlap between the guest atom and the cage framework is expected also to be large, leading to the efficient transfer of the valence electrons to the cage framework. The cage framework containing a large atom may accept valence electrons efficiently from the guest atom, decreasing the value of electrical resistivity due to the increased carrier concentration. We believe that this is what occurred upon substituting In for $\mathrm{Ga}$ in the cage framework. Indeed, In atoms in 


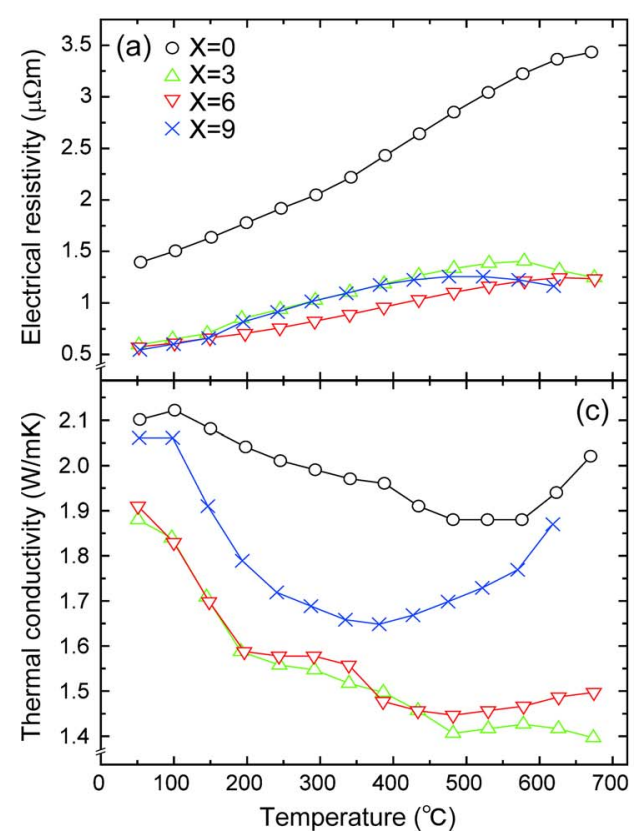

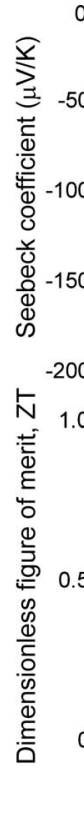

0 (b)

(b)

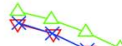

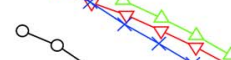
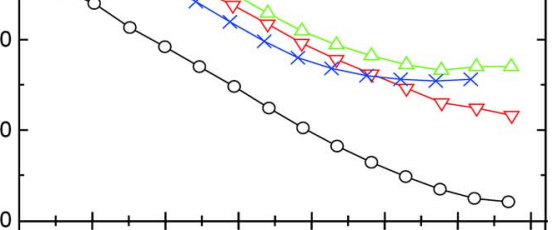

(d)

(d)

FIG. 4. (Color online) Temperature dependence of (a) electrical resistivity, (b) Seebeck coefficient, (c) thermal conductivity, and (d) dimensionless figure of merit (ZT) for $\mathrm{Ba}_{8} \mathrm{Ga}_{16-x} \mathrm{In}_{x} \mathrm{Ge}_{30}$ alloys.

$\mathrm{Ba}_{8} \mathrm{In}_{16} \mathrm{Ge}_{30}$ are reported to preferentially occupy $6 c$ sites with the maximum occupancy of 0.5 (Ref. 17). The values of electrical resistivity for specimens with $x=3,6$, and 9 are all comparable with one another and are about one-third that for $\mathrm{Ba}_{8} \mathrm{Ga}_{16} \mathrm{Ge}_{30}$ [Fig. 4(a)]. This result is consistent with the site-occupancy behavior of In atoms in $\mathrm{Ba}_{8} \mathrm{In}_{16} \mathrm{Ge}_{30}$ if we assume that half the $6 c$ sites are already occupied by In atoms in the type-I clathrate compound with $x=3$.

\section{B. Lattice thermal conductivity}

With the Wiedemann-Franz approximation, ${ }^{18}$ we estimated the electronic $\left(\lambda_{\text {electron }}\right)$ and lattice $\left(\lambda_{\text {lattice }}\right)$ contribution to thermal conductivity with the use of the following equation:

$$
\lambda_{\text {lattice }}=\lambda_{\text {total }}-\lambda_{\text {electron }}=\lambda_{\text {total }}-\frac{L_{0} T}{\rho}\left(\frac{k_{B}}{e}\right)^{2},
$$

where $k_{B}$ is Boltzmann's constant, $e$ is the electron charge, and $L_{0}$ is a constant $\left(\pi^{2} / 3\right.$ for metallic conductors and 2 for semiconductors; we adopted $L_{0}=2$ for the present case). The calculated value of lattice thermal conductivity is plotted in Fig. 5 as a function of temperature. The value of lattice thermal conductivity decreases with the increase in the In content until $x$ reaches 6 . The relatively large value of lattice thermal conductivity for the specimen with $x=9$ is due most probably to the high thermal conductivity of the incorporated other phases such as In and Ge. ${ }^{19}$

The value of lattice thermal conductivity of type-I clathrate compounds in the $\mathrm{Ba}-\mathrm{Ga}-\mathrm{Ge}$ system decreases with the increase in the split distance in the $\mathrm{Ba}(2)$ guest atom site. ${ }^{13}$ At the same time, the split distance in the guest atom site depends on the size of the encapsulating polyhedral cage. Since the lattice constant of the In-substituted type-I clathrate compounds investigated in the present study increases with the increase in the In content [Fig. 2(b)], the size of the encapsulating tetrakaidecahedral cage and thus the split distance in the $\mathrm{Ba}(2)$ site is expected to increase with the in- crease in the In content. Then, the value of lattice thermal conductivity is expected to decrease with the increase in the In content. This is exactly what is experimentally observed in $\mathrm{Ba}_{8} \mathrm{Ga}_{16-x} \mathrm{In}_{x} \mathrm{Ge}_{30}$ alloys.

\section{Dimensionless figure of merit}

The $Z T$ value of the ternary alloy $\mathrm{Ba}_{8} \mathrm{Ga}_{16} \mathrm{Ge}_{30}$ is improved by In additions to the extent that the $Z T$ value exceeds unity for the $\mathrm{Ba}_{8} \mathrm{Ga}_{10} \mathrm{In}_{6} \mathrm{Ge}_{30}$. This is due to the decrease in electrical resistivity as well as in thermal conductivity upon alloying with In. For improving the thermoelectric properties of type-I clathrate compounds in the Ba-Ga-Ge systems, it seems important to choose alloying elements that are large in size and preferentially occupy some particular cage atom site so that such additions lead to the increase in the lattice constant and the efficient transfer of valence electrons from the guest atoms. Of course, the

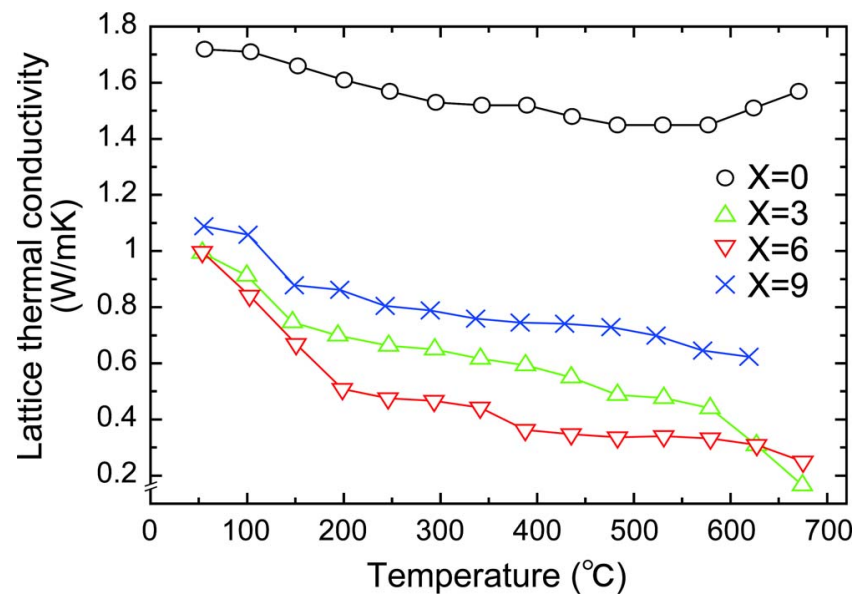

FIG. 5. (Color online) Lattice thermal conductivity for $\mathrm{Ba}_{8} \mathrm{Ga}_{16-x} \mathrm{In}_{x} \mathrm{Ge}_{30}$ alloys plotted as a function of temperature. 
amount of their additions should be chosen so that the complete charge compensation is achieved in the nominal compositions.

\section{CONCLUSIONS}

The solid solubility of indium in $\mathrm{Ba}_{8} \mathrm{Ga}_{16} \mathrm{Ge}_{30}$ is determined to be between $x=6$ and 9 when expressed in the form of $\mathrm{Ba}_{8} \mathrm{Ga}_{16-x} \operatorname{In}_{x} \mathrm{Ge}_{30}$.

The lattice constant of the type-I clathrate compounds increases with the increase in the In content, which is due to the relatively large atomic radius of In atoms in comparison with those of $\mathrm{Ga}$ and $\mathrm{Ge}$ atoms.

The values of electrical resistivity and lattice thermal conductivity for the In-substituted alloys are smaller than those for $\mathrm{Ba}_{8} \mathrm{Ga}_{16} \mathrm{Ge}_{30}$. The decrease in electrical resistivity is explained in terms of the In occupancy behavior in the $6 c$ sites, while that in lattice thermal conductivity in terms of the increased extent of the rattling motion of $\mathrm{Ba}$ guest atoms due to the increased lattice constant.

The $Z T$ value of the ternary alloy $\mathrm{Ba}_{8} \mathrm{Ga}_{16} \mathrm{Ge}_{30}$ is improved by In additions to the extent that the $Z T$ value as high as 1.03 is obtained at $670{ }^{\circ} \mathrm{C}$ for $\mathrm{Ba}_{8} \mathrm{Ga}_{10} \mathrm{In}_{6} \mathrm{Ge}_{30}$.

\section{ACKNOWLEDGMENTS}

This work was supported by Grant-in-Aid for Scientific Research (a) from the Ministry of Education, Science and Culture (No. 18206074) and in part by the 21st Century COE (Center of Excellence) Program on United Approach for New Materials Science from the Ministry of Education, Science and Culture. One of the authors (N.L.O.) greatly appre- ciates the supports from Research Fellowships of the Japan Society for the Promotion of Science for Young Scientists.

${ }^{1}$ G. S. Nolas, J. L. Cohn, G. A. Slack, and S. B. Schujman, Appl. Phys. Lett. 73, 178 (1998).

${ }^{2}$ G. A. Slack, CRC Handbook of Thermoelectrics, edited by D. M. Rowe (CRC, Boca Raton, Florida, 1995), p. 407.

${ }^{3}$ G. S. Nolas, J. Sharp, and H. J. Goldsmid, Thermoelectrics-Basic Principles and New Materials Developments (Springer-Verlag, Berlin, Germany, 2001), p. 191.

${ }^{4}$ B. Eisenmann, H. Schäfer, and R. Zagler, J. Less-Common Met. 118, 43 (1986).

${ }^{5}$ T. Hahn, International Tables for Crystallography: Space-Group Symmetry, 4th ed. (Kluwer Academic, Boston, MA, 1996), Vol. A.

${ }^{6}$ J. Dong, O. F. Sankey, and C. W. Myles, Phys. Rev. Lett. 86, 2361 (2001).

${ }^{7}$ J. S. Tse and W. A. White, J. Phys. Chem. 92, 5006 (1988).

${ }^{8}$ G. S. Nolas, T. J. R. Weakley, J. L. Cohn, and R. Sharma, Phys. Rev. B 61, 3845 (2000)

${ }^{9}$ B. C. Sales, B. C. Chakoumakos, R. Jin, J. R. Thompson, and D. Mandrus, Phys. Rev. B 63, 245113 (2001).

${ }^{10}$ N. L. Okamoto, M. W. Oh, T. Nishii, K. Tanaka, and H. Inui, J. Appl. Phys. 99, 033513 (2006).

${ }^{11}$ N. L. Okamoto, K. Tanaka, and H. Inui, Acta Mater. 54, 173 (2006).

${ }^{12}$ N. L. Okamoto, K. Kishida, K. Tanaka, and H. Inui, J. Appl. Phys. 100, 073504 (2006).

${ }^{13}$ N. L. Okamoto, J. H. Kim, K. Tanaka, and H. Inui, Acta Mater. 54, 5519 (2006).

${ }^{14}$ L. Pauling, The Nature of Chemical Bond, 3rd ed. (Cornell University Press, New York, 1960).

${ }^{15}$ S. Paschen, W. C. Cabrera, A. Bentien, V. H. Tran, M. Baenitz, Y. Grin, and F. Steglich, Phys. Rev. B 64, 214404 (2001).

${ }^{16}$ N. P. Blake, S. Latturner, J. D. Bryan, G. D. Stucky, and H. Metiu, J. Chem. Phys. 115, 8060 (2001).

${ }^{17}$ A. Bentien, E. Nishibori, S. Paschen, and B. B. Iversen, Phys. Rev. B 71, 144107 (2005); In Table IV, the occupancies of In atoms in $6 c, 16 i$ and $24 k$ sites should be replaced with the occupancies of Ge atoms to be consistent with the chemical composition of $\mathrm{Ba}_{8} \mathrm{In}_{16} \mathrm{Ge}_{30}$.

${ }^{18}$ G. D. Mahan and M. Bartkowiak, Appl. Phys. Lett. 74, 953 (1999).

${ }^{19}$ D. R. Lide, Handbook of Chemistry and Physics, 82nd ed. (CRC, Boca Raton, Florida, 2001). 